disease and the râles at the base of the left lung remained. Blood was still present in the urine, but no casts could be detected. He usually took his food with appetite.

Sept. 9th.-At 3 A.m. patient had a rigor, which lasted ten minutes; after the rigor slight facial paralysis was observed on the left side. At 10 A.M. could not move the left leg, but was still sensible, and took nourishment. At 2 P.M. he was visited by Dr. Green, Dr. Headland being out of town, when he was semi-comatose, and had quite lost the power of the left side. The face was drawn to the opposite side.

From this time he gradually sank, and died at 8 P.M. on September 11th.

The autopsy was made the following day by Dr. Green. The heart was dilated, more especially the left ventricle, the walls of which were extremely thin. A large portion of the mitral valve was destroyed by an atheromatons ulcer, on the margins of which were several vegetative masses. Each kidney presented several yellowish organised infarcts. In the spleen was a large wedge-shaped infarct. The membrane on the posterior lobes of the brain was hyperæmic, and many of the vessels at the base were plugged with thrombi, and the left optic thalamus was softened. The lungs were odematous, the lung-tissue being tougher than natural.

\section{LEEDS PUBLIC DISPENSARY.}

FEMORAL ANEURISM ; LIGATURE OF EXTERNAL ILIAC ARTERY ; RECOVERY.

(Under the care of Mr. JEssor.)

SAmutr S-, aged thirty-seven, applied at the Leeds Pablio Dispensary on Oct. 16th, 1868, on account of a large swelling which had recently formed on his left thigh just below the groin. Mr. Shaw, of Louth, who at that time filled the office of senior house-surgeon, at once communicated with Mr. Jessop, who then took charge of the case. The patient said that his family was a remarkably healthy one, ànd he himself, though short in stature, was muscular and equal to great exertion. He had always been sober. When twenty-five years old he had a chancre, with suppurating buboes, and these were not followed by any constitutional symptoms. His occupation for many years had been that of a striker in a mechanic's shop. Whilst lifting his hammer, which weighed twelve pounds, he had been accustomed to rest the point of the handle against the front of his left thigh, and to repeated injuries thus caused he attributed his ailment.

In May, 1868, he began to suffer from occasional shooting pains in the thigh, knee, and leg; and during the first week in September his attention was arrested by a prominent swelling, not larger than a marble, which "l beat like a heart." By the first week in October the swelling had gradually attained the size of a hen's egg, pulsation being very distinct; and towards the end of that week a sudden enlargement took place. He could nolonger feel any pulsation; the pain became much more intense, and he was compelled to give up bis work. Thinking that a "gathering" was about to form, he took to his bed, and endeavoured to "bring it forward" by means of poulticing. This treatment was still being continued when first seen by Mr. Shaw on October 16th.

Occupying the whole width of the limb, and extending from two fingers' breadth below Poupart's ligament to the middle of the thith, was a prominent, dusky, semi-solid swelling, in which a very faint distensile pulsation could be both seen and felt, and over whose whole surface a wellmarked soft bruit could be heard. Compression of the artery at the groin caused immediate cessation of the beating, but gave rise to very little, if any, diminution in the size of the swelling. No pulsation could be felt in the artery below, either in the ham or at the ankle. The appearance of the limb elsewhere was natural, and the temperature of the two limbs was equal. A most careful examination failed to elicit any evidence of other disease. He complained of pains in the lumbar spine, and in the thigh and leg. He had frequent attacks of cramp in the calf, and the whole limb felt numb and lifeless. On October 17 th the swelling had decidedly extended in an upward direction, and as on the 18 th it had reached as high as Poupart's ligament, it was decided without delay to tie the external iliac artery. This was accordingly done by Sir Astley Cooper's method, a strong silk lioature, one end of which was left hanging out of the wound, being used for securing the vessel. One small artery, divided during the operation, was secured by ligature. 'The edges of the wound having been brought together by wire sutures, and covered with a compress of lint, the whole limb was wrapped in cotton wool and flannel.

Without entering upon a daily detail of symptoms which, with few and unimportant exceptions, were of a favourable character, the following is a brief statement of facts. The t.emperature of the sole of the foot reached its lowest point five hours after operation, when the thermometer stood at $81^{\circ}$, and in three hours more it had risen to $83^{\circ}$, the right foot at the same time showing $92^{\circ}$. On the morning of October 19 th the left foot showed $91 \cdot 6^{\circ}$, and on the $20 \mathrm{th}$, $96^{\circ}$, at and after which time there was little variation between the two feet. The highest temperature in the axilla was registered on the afternoon and evening of October $19 \mathrm{hh}$, and was only $100 \cdot 3^{\circ}$, the left foot being at the same time $936^{\circ}$, and the right $963^{\circ}$.

The pulse at first ran rather high: in the evening of the day of operation it was 110 ; on the morning of October 19 th, 128; and in the evening of the same day, 132. On the 20 ,h it had come down to 120 , and on the 21 st to 102 . From this time it diminished in frequency until Oct. 30th, when it counted 90.

Subcutaneous injections of morphia were given during the four days following the operation, for the relief of pains in the back and body.

Daily observations were made as to the condition of the limb. On October 21st its appearance was quite natural; on the 27 th the heel was congested, a livid spot was noticed behind the inner malleolus, and the veins of the calf were more prominent than before. On November 1st, the veins had subsided, and the livid spot had faded; and on November 12th the limb had again assumed a natural appearance.

On the evening of the operation the aneurism felt hard, and no pulsation could be detected in it. On October 20 th it had become soft and fluctuating, and was decidedly smaller. On the 26 th it was still fluid, but had increased in size and looked more diffused. On the 30 th it had again lessened somewhat, and was a little firmer. By Nov. 11th there $w$ ss a further diminution in its size, and fluctuation, though still apparent, was less distinct.

On Niv. 16th the ligature came away, the wound having closed with the exception of the spot from which the silk had separated.

On Nov, 29th he was allowed to sit out of bed for an hour, the aneurism being then about as large as a cricketball; and on January 8 th, 1869 , he began to walk out on crutches. His recovery proceeded steadily; but for many months the position of the aneurism was occupied by a semi-solid swelling which very slowly subsided. Considerable contraction and rigidity of the knee-joint subsequently took place, and much persevering trealment was needed to rectify it; so that it was not until the end of 1869 that he could be considered in a fit state for work. $\mathrm{He}$ is now (Sept. 1872) employed in a mechanic's shop; he walks well and firmly, making use occasionally of a stick, because of weakness in the affected limb. A little thickening in the course of the vessel in Scarpa's triangle alone remains to show the former site of the aneurism. The whole limb is a little less than the other, but it is muscular and well nourished.

The London Hospital Medical College.Distribution of Prizes, Session 1871-72.-Clinical Medicine: 2O Scholarship, Mr. W. L. Morgan. Clinical Obstetrics: $£ 20$ scholarship, Mr. W. L. Morgan. Dressers' Prizes: Mesers. C. A. Lrw, W. Lang, G. B. Sincock, H. G. Brown, W. Hurford Tudd, and J.D. Watson. Buxton Suholarships: £30 Scholarship, Mr. B. R. Rxgate; 220 Sicholarship, Mr. H. E. Price; Certificate, Mr. R. H. Fux. Human Anatomy: $£ 20$ Scholarship, Mr. R. H. Fox; Certificate, Mr. Burtonshaw. Anatomy, Physiology, Chemistry: $£ 25$ Scholarship given by the Medical Council, Mr. C. A. Mercier; Certificate, Mr. Hyde Walker. 